\title{
THE LINK BETWEEN PEOPLE AND PERFORMANCE UNDER THE EFQM EXCELLENCE MODEL UMBRELLA
}

\begin{abstract}
:
Despite the growing attention that human resources have received in the management literature, the strategic role of the HR function is still being questioned. The main target of this paper is to determine whether firms that follow the strategy, leadership and personnel suggestions proposed by the EFQM Model contributes to improve organizational performance, and also determining if the strategic management of human resources plays a mediating effect between the personnel management and the results of the company.

The study was performed using a questionnaire on a sample of 200 mediumsized industrial Spanish firms, and employing Structural Equations Modelling methodology.

Our findings suggest that, under the EFQM Model, the influence of both leadership and strategy on people allows organizations to improve their performance. Moreover, a strategic approach in the management of human resources helps to enhance the contribution of personnel in the results of the company. This fact had not been broadly studied in prior literature and, moreover, it has not been found any joint framework linking leadership, strategy, personnel, strategic human resource management and performance in QM organizations.

This study helps managers to identify what types of strategy and relationships with their staff can be most effective in improving the company's results. At the same time, it is a stimulus for the personnel directors who defend a strategic approach to the human resources function in their companies.
\end{abstract}

Keywords- EFQM, SHRM, PERFORMANCE, LEADERSHIP, STRATEGY, 


\section{PEOPLE.}

Word count.- 9656

\section{Introduction.}

A common aim for companies is to obtain and maintain sustainable competitive advantages over time (Corredor \& Goñi, 2010). In this sense, in recent decades, the concept of Total Quality Management (TQM) has spread as an essential management strategy to get this target. TQM is defined as a company philosophy that concerns all employees and helps to achieve competitive advantage and meet customer demands. It embraces hard and soft factors, where hard factors are related to technical aspects (such as statistical process control or quality function deployment) and soft factors include organizational culture, leadership styles, employee engagement and human resource practices (A. Calvo-Mora, Picón, Ruiz, \& Cauzo, 2013).

The interest in the study of these factors has transcended the academic literature and has resulted in several TQM prizes. Three of the most famous and now widely used frameworks for TQM are the Deming Model (Japan), the Malcolm Baldrige Model (USA) and the EFQM Model (Europe). All three provide tools and methods to improve processes (Corredor \& Goñi, 2010).

In the concrete case of the European Foundation for Quality Management (EFQM), it is the custodian of the EFQM Excellence Model. This model is a non-prescriptive management framework that is widely used by over 30.000 public and private sector organizations in the world. This model helps managers to identify the main aspect to be improved for attaining Excellence and can be applied in any organization (EFQM, 2013; Zink \& Schmidt, 1995). The Model includes nine criteria and scientists and managers have established three linkage axes in the model, where the 'Personnel Axis' links the criteria Leadership, People, Processes, People Results and Business Results (Nabitz, Jansen, Van der Voet, \& Van den Brink, 2009). In this sense, most of the studies have 
focused their attention on evaluating the impact of the EFQM model on business results (Gómez-López, Serrano-Bedia, \& López-Fernández, 2016), although some, such as the one of Samuelsson and Nilsson (2002) centred its attention on the fact that self-assessment approaches contribute to the improvement of the organization and encourage employee involvement. Similarly, literature on quality management (QM) has shown the positive effects that the adoption of QM systems and models have for performance management (Bayo-Moriones, Merino-Díaz-de-Cerio, Escamilla-de-León, \& Selvam, 2011). However, Gómez-López et al. (2016) state that EFQM's enablers do not always have a significant effect on results. Moreover, Doeleman, Ten Have, and Ahaus (2013) cautioned that best practices do not necessarily guarantee performance improvements.

Although the relationship between EFQM's enablers and companies' results has been reasonably studied (Santos-Vijande \& Álvarez-González, 2007), recent literature has tried to analyse which specific factors analysed in these models contribute most intensively to improve the results of the companies. Concretely, following Bayo-Moriones, Merino-Díaz-de-Cerio, et al. (2011), three dimensions are considered fundamental in any implementation of TQM, in order to achieve a significant impact on results: personnel and human resource policies, strategic management of partnerships and management of resources and processes. In this regard, these authors remark the importance of on Human Resource Management (HRM) on quality management.

However, only few papers have analysed potential mediators between EFQM criteria. This is even more scarce in strategy, leadership and human resources issues. That is why some authors, such as Gómez-López et al. (2016), suggest that future research should take into account the factors that facilitate or interfere with the path to excellence.

Moreover, our study also answers to recent calls for more research adding a framework that shows if the implementation of an EFQM model focused on a concrete type of Leadership, can enhance performance through HRM and 


\section{SHRM.}

The previous literature stated that human resources, leadership and strategy are essential for managing excellence companies. In terms of human resources, they have always been considered broadly essential to obtain competitive advantages. However, it is only in the last decades that it was understood as a crucial element, motivated by the emergence of the perspective of Strategic Human Resource Management (SHRM) (C. A. Lengnick-Hall, Beck, \& Lengnick-Hall, 2011). SHRM covers the overall HR strategies adopted by business units and companies and it tries to underline the contribution of the personnel function on performance (M. L. Lengnick-Hall, Lengnick Hall, Andrade, \& Drake, 2009; Sparrow, 2016). This strategic orientation is aligned with the approach adopted by the EFQM model. It is said that business excellence models add a strategic dimension to TQM, underpinning rational elements within its criteria. It ensures that companies that, officially or unofficially, follow the model adopt a comprehensive strategic approach, leading to superior performance. Related to HRM, Canet-Giner and BalbastreBenavent (2011) found a direct effect between the needs and expectations of employees and their impact on People's results and company performance, but without consideration of specific leadership or strategy styles. However, as Escrig and de Menezes (2015) suggest that there is a lack of research on whether and how facilitators, specially HRM practices, contribute to superior performance.

Other important aspect related to human resources is the leadership style of these organizations. Some studies, such as Laureani and Antony (2017), have analysed the key factors that managers in continuous improvement organizations should count on. Likewise, these authors investigated whether different leadership styles could condition job and firm performance (Masa'deh, Obeidat, \& Tarhini, 2016). Similarly, Chadwick, Super, and Kwon (2015) suggested that the leaders emphasis on SHRM has effects on the performance of companies through the put into practice of determined HR practices, but the 
research did not analyse leadership effects.

Finally, the strategy is considered as a very relevant driver to achieve the objectives set by management with great implications throughout the company. Related to strategy in QM organizations, Prajogo and Sohal (2006) identified a positive relationship between strategy, TQM and performance, although without a specific analysis of HRM.

Thus, as a matter of fact, in the practice, it becomes difficult to find a perfect link between a firm constraints, such as HRM, leadership or strategy and performance measurement frameworks (Wongrassamee, Gardiner, \& Simmons, 2003). In fact, there is no empirical framework linking the Leadership, People, Strategy, SHRM suggested by the EFQM Model and performance. In this sense, Wongrassamee et al. (2003) indicate that future research should focus on how to implement strategic performance frameworks meaningfully. Moreover, Van Schoten, de Blok, Spreeuwenberg, Groenewegen, and Wagner (2016) suggest that more research is needed to demonstrate the advantages of implementing the criteria of the EFQM Model and SHRM in an organization.

To shed light on this topic, our study contributes to this growing body of literature by addressing the following research questions: How do leadership, strategy and human resources contribute to improving organizational performance? Does SHRM mediate the expected positive relationship between the personnel criteria and the performance of the company?

To answer these questions, first, we focus on the importance of the adoption of a leadership style that may have influence over People criterion for attaining competitive advantages in EFQM organizations. In this sense, the majority of the authors recognise the effect of leaders on an organization. Although this is well understood, the style of leadership that managers may adopt in QM organizations in order to develop consistent HRM practices that have a strategic impact over performance, is not clear. That is, the kind of leadership promoted by quality models in order to enhance HRM and performance in organizations is under debate. 
Secondly, we have not been able to determine in prior literature whether SHRM plays a mediating role between some of the criteria of the EFQM model and performance in organizations, and therefore this research seeks to determine whether SHRM plays a determining role in organizations that follow QM systems.

This study provides significant contributions to the QM literature. We provide an integrated framework linking SHRM and the EFQM model, through its criteria People, Leadership and Strategy, that it is tested in a sample of 200 companies. This respond to the recent calls for more research regarding these relationships. Moreover, the present study advances a more fine-grained understanding of the strategic role of human resources management to achieve competitive advantages with its human resources. This is of great interest due to the importance of personnel in the soft dimensions of TQM and the strategic perspective adopted for the current version of the EFQM Model.

The paper is structured as follows. Next section studies the EFQM Model, its criteria and the SHRM perspective that the Model proposes from a theoretical perspective. Several hypotheses regarding the impact of the adoption of EFQM criteria over other criteria and over performance are then formulated. Section three describes the main characteristics of the database used in the empirical analysis, as well as the variables used and the methodology employed in order to test the developed hypotheses. Section four discusses the results obtained and, finally, the main conclusions of the research are presented.

\section{Literature Review.}

As we have shortly introduced previously, the EFQM Excellence model has been defined as a model that allows the organizations, through several criteria, to understand the position that they occupy in the market and to use the information acquired in the self-assessment, in order to improve the whole organization (Dijkstra, 1997; Doeleman et al., 2013). 


\subsection{The EFQM Model}

In 1988, fourteen of the major European companies formed the European Foundation for the Quality Management. This foundation has as goal, namely, to help European companies to be more competitive in the world market and raise awareness that Excellence is essential for the process of continuous improvement.

The EFQM is built on nine criteria grouped into two sections (Figure 1), five criteria for enablers (Leadership, Strategy, People, Alliances \& Resources, Processes, Products and Services) and four criteria for results (Customer results, People results, Society results, Key performance results). While enabler criteria show how things are done in the organization, results criteria illustrate what is achieved by the enablers.

\section{Figure 1: The EFQM Excellence Model}

The EFQM Excellence model suggests causal relationships between and within enablers and results. Some previous papers advance the hypothesis that there is a close relationship between enablers and results of EFQM (Bou-Llusar, Escrig, Roca, \& Beltran, 2005; A. Calvo-Mora, Leal, \& Roldán, 2006). However, this association is only partially analysed in the literature.

In this sense, one of the enablers that appears in the model is the criterion "People". This criterion underlines the importance of the HR function for the success of companies. According to EFQM (2013), it emphasizes the importance of practices like selection and management of professional careers, training and development, teamwork, performance appraisal, communication and rewards and remuneration.

However, before analysing the effect on performance that the People criterion may have under the Excellence model, it is necessary to examine the main predictors that influence it: the Strategy and Leadership criteria. This analysis will help to understand how the implementation of these criteria jointly may 
provide answers for differences in performance.

\subsubsection{Strategy.}

Competitive strategy is viewed as a combination of the ends (goals) for which the firm is striving and the means (policies) by which it is seeking to get there (Galpin \& Whittington, 2012). Organizational strategy determines the main objectives, actions and policies in the future for all organizational functions, and more concretely for the personnel department. Moreover, when technological, economic and demographic changes are pressing organizations to adopt more effective HRM (Xie, 2007; Zhu, Cooper, Thomson, De Cieri, \& Zhao, 2013), a good fit between organizational strategy and human resource practices is even more important (Cappelli \& Crocker-Hefter, 1996; Sun \& Pan, 2011).

Good strategic alignment will improve the involvement of the employees, stimulating their know-how and their skills. In this sense, organizational managers have realized the importance of employee learning, training and commitment in order to improve organizational performance (Park \& Jacobs, 2011). In this regard, Wan Hooi and Sing Ngui (2014) suggested that strategy and HR practices should be developed jointly, in order to achieve a better performance in organizations.

Following the EFQM Model, the strategy of the company must act as a reference for the staff of the organization (EFQM, 2013). Therefore, the enabler Strategy of the EFQM Model should be correlated with the application of the EFQM Model principles on HRM covered by the enabler People. In fact, some studies have found a positive relationship between these two criteria of the model (Eskildsen \& Dahlgaard, 2000; Hanks, 2012; Sadeh \& Arumugam, 2010).

Thus, for instance, the subcriterion 4 of the Strategy criterion ("Implementation and communication of the policy and strategy") gathers the importance of the communication of the policy and strategy to every employee of the 
organization. So this subcriterion makes reference to the fact that the organization may align and communicate its plans, aims and goals to all its employees (EFQM, 2013).

In the same way, the subcriterion 4 of the People criterion ("Existence of dialogue among people of the organization") refers to the value of the identification of the communication needs in an organization, as well as the development of policies and strategies based on those needs (EFQM, 2013).

Thereby, the new perspective in HRM suggests that it is directly influenced by corporate strategy, considering it as critical for the survival and success of the organization (Boxall \& Purcell, 2003; Darwish, Singh, \& Mohamed, 2013).

Therefore, organizational strategy becomes an essential element that will determine the HR policies that will be implemented in it. Consequently, it could be expected to find that:

$H_{1}$ : The criterion Strategy of the EFQM model has a positive relationship with People criterion.

\subsubsection{Leadership.}

Senior management must provide leadership and be committed to creating an organizational climate/culture that promotes employee empowerment and focuses on customers' satisfaction (Ugboro \& Obeng, 2000). In fact, following Baptiste (2008) and Vermeeren, Kuipers, and Steijn (2014), leadership is a determinant of employees' satisfaction, which enhances organizational results. Moreover, leadership can be considered to encourage employees' empowerment and commitment through challenging work conditions (Asag-Gau \& Dierendonck, 2011; Gillet \& Vandenberghe, 2014). Therefore, managers must create and promulgate the values and philosophy of the organization, as well as the goals consistent with these values to achieve them (Eskildsen \& Dahlgaard, 2000; Hanks, 2012). 
Leaders continuously motivate and encourage the people they cooperate with and act as a reference model for behaviour and performance, demonstrating their ability to adapt the course of the organization in relation to an external environment that changes continuously (Vermeeren et al., 2014). Concretely, from the different types of leadership that exist, transformational leadership strives to align the values and goals of employees with those of the organization by influencing or altering their values, beliefs and attitudes through internalization or identification (Menguc, Auh, \& Shih, 2007). Transformational leaders encourage employees to have a sense of belonging, duty, commitment and stimulation in order to achieve their objectives and values (Gillet \& Vandenberghe, 2014; MacKenzie, Podsakoff, \& Rich, 2001).

Concretely, and regarding the EFQM Model, it defines leadership as follows: "Excellence is to carry out a leadership with vision capability that serves as inspiration for others and that is coherent in the whole organization" (EFQM, 2013). Since Lowe, Kroeck, and Sivasubramaniam (1996) and Doeleman, ten Have, and Ahaus (2012) considered a transformational leader as the one that is committed to others in such a way, that the leader and the follower mutually arise in themselves a higher level of motivation and morality, it may be observed a clear relationship between EFQM Leadership and transformational leadership.

Furthermore, there is an important field of the literature that has found evidence suggesting that leadership is a critical component of the effective management of employees (Asag-Gau \& Dierendonck, 2011; Vermeeren et al., 2014). This conclusion is also supported by studies that have tested EFQM models suggesting the existence of a link among the criteria of Leadership and People (A. Calvo-Mora et al., 2006; Doeleman et al., 2013; Sadeh \& Arumugam, 2010). Specifically, by examining in depth the EFQM Model, it may be observed that there is a close relationship among several subcriteria of the Leadership and People criteria. For instance, the subcriteria 4 of the Leadership criterion, named "Motivation, support and recognition of People on behalf of 
leaders" is related to the subcriteria 3 and 5 of the People criterion, called respectively "Involvement and liability assumption on behalf of People" and "Compensation, recognition and attention to People" (EFQM, 2013). In this sense, following Bayo-Moriones, Bello-Pintado, and Merino-Diaz-de-Cerio (2011) and Youssef, Youssef, and Ahmed (2014), the presence of quality systems in an organization such as the EFQM model, efficiently led, may have a significant and positive effect in the adoption of flexible work practices issued to the promotion of the employees, their involvement and empowerment. In this regard, and according to Baptiste (2008), the type of leadership promoted by the EFQM Model is determinant for HRM.

For all these reasons, it could be expected that:

$\mathrm{H}_{2}$ : The criterion Leadership of the EFQM model has a positive relationship with People criterion.

Trustful and cooperative leaders enhance the alignment process between leadership and strategy of an organization (Heavey \& Murphy, 2012). That is, leaders have to take their organizations into the future by implementing strategies that lead them towards more favourable outcomes.

Leadership practices being developed in a coherent way aligned with an Excellence model have been shown to enhance business strategy, creating positive synergies on it (Laschinger \& Fida, 2015; Zarrabi \& Vahedi, 2012).

Specifically, the EFQM Model indicates that excellent leaders develop and facilitate the prosecution of the mission and vision of an organization. Likewise, they encourage the organizational values and the different systems required to achieve a sustainable success over time (EFQM, 2013).

In fact, the EFQM Model establishes how everything planned (the strategy) may be put into practice on behalf of leaders, through a series of actions led to continuous improvement and the generation of value for the stakeholders (A. Calvo-Mora et al., 2006; Prabhakar \& Yaseen, 2016). 
Thus, the EFQM (2013) also posits a positive relationship between its criteria Leadership and Strategy. Following this line of thought, several empirical studies support this association (Raharjo et al., 2015; Sadeh \& Arumugam, 2010; Suarez, Calvo-Mora, \& Roldán, 2016).

Similarly, a link among several subcriteria of the criterion Leadership and the criterion Strategy may exist. For instance, the subcriterion 1 of the Leadership criterion is focused on the "Development of the mission, vision and values on behalf of employees". In the same way, the subcriterion 2c of the Strategy criterion is concentrated on the "Development, review and update of the policy and strategy".

As the close relationship between the criteria Leadership and Strategy of the EFQM Model suggest, and as A. Calvo-Mora et al. (2006) and Hanks (2012) concluded, organizational leaders are the ones that should create and transmit the values and aims of an organization, as well as the development of a strategy to accomplish them.

Therefore, the following hypothesis could be put forward:

$H_{3}$ : Leadership criterion, according to the EFQM model, has a positive relationship with Strategy.

\subsubsection{A Strategic HRM Perspective.}

The new perspective on HRM suggests that people management directly influences the implementation of strategic organizational targets and operations (Bonavia \& Marin-Garcia, 2011) contributing to improve organizational efficiency (Gao, Zhou, \& Wu, 2016). SHRM can be defined as the pattern of planned human resource development and activities intended to enable an organization to achieve its goals (Knies, Boselie, Gould-Williams, \& Vandenabeele, 2017; P.M. Wright \& McMahan, 1992). Consequently, SHRM focuses in the development of HR activities for sustaining the competitive strategy of the company (P. M. Wright \& Snell, 1991) with the aim of 
improving organizational performance (Ali, Lei, \& Wei, 2017) and developing an organizational culture that fosters innovation and flexibility.

All personnel policies have to be captured by an HRM strategy. This can be understood as the orientation adopted by the organization to direct human aspects related to employees, giving an internal cohesion to these activities in its general implementation (P. M. Wright \& Snell, 1991).

However, the important point of this new perspective on HRM is to consider that the function of HRM is critical for the survival of the company and its success (Boxall \& Purcell, 2003; Pattanayak \& Sahoo, 2017). From this statement, two main perspectives have been developed: content and process approaches.

On the one hand, the content approach defines HRM policies with the aim of obtaining improvements in organizational performance (Maleyeff, 2006), so that HRM has to be integrated with the strategy and be implemented in the daily work (C. A. Lengnick-Hall et al., 2011). Many studies have tried to link HRM with competitive advantage (e.g. (Ali et al., 2017; Boxall and Purcell (2003))), identifying a positive relationship. In fact, skilled workers that are not motivated through HRM practices are difficult to contribute to performance (Bonavia \& Marin-Garcia, 2011).

However, under this strategic approach, Delery and Doty (1996) distinguished three perspectives for studying the impact of HRM on performance: universalistic, contingent and configurational. The universalistic view maintains that there are some HRM practices, called as 'best practices', that have a positive influence on the organizational performance of all the companies, whatever their characteristics (e.g. (Delery \& Doty, 1996; Saridakis, Lai, \& Cooper, 2017)). The contingent view maintains that there are no best HR practices, because, in order to be effective, HR practices must be consistent with other aspects of the organization, specifically with its strategy (Akhtar, Ding, \& Le, 2008). Finally, the configurational approach maintains the importance of implementing internally consistent HRM practices, rather than isolated 
practices, in order to affect performance (Tzabbar, Tzafrir, \& Baruch, 2017; P. M. Wright, Dunford, \& Snell, 2001).

In the case of the EFQM model, a number of HRM policies appear under the People criterion for excellent organizations. Thus, HR practices should be taken into account when a quality model or system is developed inside an organization (Martínez-Jurado, Moyano-Fuentes, \& Gómez, 2013).

That is, for example, organizations should motivate or train their employees, and involve them in the improvement processes that the model suggests (Eskildsen, 1998; Matthies-Baraibar et al., 2014). From the perspective of the EFQM model, it is clear that the People criterion is positively related to organizational performance. Furthermore, according to EFQM (EFQM, 2013), it is designed to care for, communicate, reward and recognize, in a way that motivates people, builds commitment and enables them to use their skills and knowledge for the benefit of the organization. This may develop innovative HRM practices that will lead to a superior performance (Cañibano, 2013). Thus, HRM, considered in relation to the People criterion may contribute to improved organizational performance, provided that these HR practices encourage committed and efficient employees (Tracey, 2012). Therefore, the following hypothesis is proposed:

H4: People management, according to the EFQM model, has a positive influence on performance.

On the other hand, the SHRM process approach analyses how to design the HRM strategy to attain a competitive advantage. From this perspective, the literature identifies two orientations: proactive and reactive. Proactive approaches are followed by those companies that link their human resource management practices with their business strategy and mobilize the ability and actions of organizational members toward the firm's goals. Furthermore, HR managers may participate in the design of corporate strategy. Thus, HRM will contribute to the implementation of the firm's strategy (M. L. Lengnick-Hall, 
Lengnick-Hall, \& Rigsbee, 2012). In contrast with this, a reactive approach provides answers to essential questions (Harpaz \& Meshoulam, 2010), adapting HR to a previous organizational strategy that has be developed without consideration of the main HRM aspects. According to literature, SHRM should adopt a proactive perspective to help organizations to define and to implement their strategies (Chadwick et al., 2015).

Furthermore, according to the EFQM, it is necessary to align HRM with the strategy of the company (A. Calvo-Mora et al., 2006). The literature in this field shows the benefits of adopting proactive HRM strategies (Cañibano, 2013). These arguments are also taken into account by the People criterion of the EFQM model. Moreover, as the EFQM Model encourages the organizational strategy to be highly aligned with HRM, HR managers should participate in the design of the corporate strategy (M. L. Lengnick-Hall et al., 2012). As a result, it is expected that organizations that perform better on the People criterion will adopt proactive SHRM, because, as noted above, this perspective has been broadly related with organizational performance (Muindi, 2017; Ngo, Lau, \& Foley, 2008; Singh \& Singh, 2014).

As a consequence, it is suggested that the People criterion will have a positive effect on performance, but it is necessary to adopt a strategic approach to HRM in order to obtain the best results. For this reason, mediating role of the SHRM orientation is proposed in the last hypothesis:

H5: A SHRM orientation plays a mediating role between People criterion according to the EFQM model and performance.

\section{Methodology}

\subsection{Population and Sample}

The population used in this study includes Spanish manufacturing organizations from different sectors with between 50 and 500 employees and more than five years of existence. Using the SABI (Iberian Balances Analysis System) 
database, 3814 companies with these characteristics were identified.

The information was collected with a structured questionnaire via a webpage designed for the purpose, reinforced via telephone. The questionnaire was previously tested in some companies and by experts of different Spanish universities in the pilot phase. Then, the final process was carried out by a company specialized in the execution of these questionnaires.

In order to eliminate one of the most frequent forms of bias, we used multiple informants from each company, enhancing the validity of the research findings. In this case, we have directed our research focus to four managers at each company: quality, operations, marketing and HR managers. Each manager answers a common section of the questionnaire (related to the EFQM model) and a second section specific to their function in the company (i.e. personnel managers provide information about strategic perspectives in the HRM, culture, and so on).

We randomly contacted with 871 companies and obtained 800 valid questionnaires (four managers answered for each of the 200 companies that participated in the study). The unit of analysis for this study was the company. The sample was composed of medium sized companies: $45.0 \%$ of the sample had 50 to 99 employees, $30.5 \%$ had 100 to 250 employees and $24.5 \%$ had 250 to 500 employees. The characteristics of the 200 companies of the final sample are summarized in Table 1. Our sample was not made of companies that were applying the EFQM Model in an active way, but we consider that all companies of the sample, although without consciousness in most of the cases, follow some of EFQM Model recommendations in a certain degree, since these recommendations are of general knowledge in the world of management.

\subsection{Measures.}

The design of the questionnaire was based on a discussion of the literature. For all the measures we used a Likert scale of 5 points (1="Strongly disagree"; $5=$ "Strongly agree"). 


\section{EFQM variables}

To measure them, the EFQM model sub-criteria were used as a guide for developing the final questionnaire.

The different subcriteria were evaluated to avoid duplication, and the list was reduced to 64 items. In this paper we have used 10 items for measuring Leadership, 8 items for Strategy, 10 items for People criterion and 16 items for measuring performance (four for each Results' criterion).

When the EFQM model is used to evaluate a company, it is computed as an index. Therefore, following the methodology used in the application of the EFQM model, these four criteria were processed as formative constructs in coherence with previous researches (Sadeh, Arumugam, \& Malarvizhi, 2013). In addition, it is important when using a formative construct to build the index based on a large number of indicators, thereby ensuring that they have tapped into the multidimensional and multifaceted domain of the construct (Bollen \& Lennox, 1991).

\section{SHRM}

While the operationalization of the model relied primarily on formative measures (where the measure itself is taken as the true representation of the variable's value), a reflective measure (where the measurement items "reflect" or are driven by an underlying latent variable they represent) was used for the measuring of the strategic behaviour of the company, HRM. This construct reflects the adoption of SHRM practices that are internally consistent and compatible with the firm's strategy. The study of Wei, Liu, Zhang, and Chiu (2008) based on previous literature (Ngo et al., 2008) was used to define the scale of measurement for the adoption of SHRM practices. 10 items for SHRM were measured and just the HR manager of the company answered the items of this scale. Cronbach's reliability coefficient was calculated, and the alpha value was 0.871 , indicating acceptable measurement reliability. 


\section{Control variables.}

According to literature, performance could be influenced by contextual variables such as size and age of companies. In this sense, studies that have examined this question, obtain contradictory results (A. Calvo-Mora, PicónBerjoyo, Ruiz-Moreno, \& Cauzo-Bottala, 2015). Therefore, it appears that different reasons relating to the characteristics of the operations carried out or the intrinsic motivation to follow certain practices may be behind the impact of size and age on SHRM and performance in an organization and the need to explore leadership, HRM, SHR and performance as a joint framework. Thus, we have included, as control variables, the age and size of the company, measured by the number of years from its foundation and the number of employees each one has; since they could be good determinant of reliable results in the study.

Table 2 shows means and correlations among the variables used in this research.

\section{Table 2: Descriptive statistics and correlation matrix}

\section{Analysis and Results.}

Structural equations modelling methodology was employed to test the hypotheses. Conventional maximum likelihood estimation techniques were used to test the model (Jöreskog \& Sörbom, 1996), using EQS 6.1 software. The results are shown in Figure 2.

\section{Figure 2: Results of testing the hypotheses.}

The results suggest a good fit of the specification for measuring organizational learning $\left(\chi^{2}=7.606, d f=4\right.$; goodness-of-fit index $[\mathrm{GFI}]=0.989$; root mean square 
error of approximation $[\mathrm{RMSEA}]=0.067$; comparative fit index $[\mathrm{CFI}]=0.994$; non-normed fit index $[\mathrm{NNFI}]=0.967$; incremental fit index $[\mathrm{IFI}]=0.994)$. The GFI, CFI, TLI and IFI statistics are near or exceed the recommended threshold level of 0.90 (Hoyle \& Panter, 1995).

Furthermore, the RMSEA is below 0.080 and the root mean square residual [RMR] and standardized RMR are 0.005 and 0.023 , respectively, indicating an acceptable fit. The traditionally reported fit indexes are within the acceptable range.

One of our tasks was to identify if the criteria Strategy and Leadership of the EFQM model were related to People criterion, and their effect on performance in organizations. In this sense, the findings for $\mathrm{H}_{1}$ suggest that Strategy ( $\beta=0.294, p<0.001)$ has a positive and significant relationship with the People criterion, supporting the widespread view that organizational strategy may shape other departmental strategies in EFQM organizations.

\section{Table 3: Construct structural model}

Our second hypothesis focuses on the relationship between Leadership and People criterion $(\beta=0.635, p<0.001)$. The acceptance of this hypothesis helps to underline that the role of managers is a key driver of the human resource policies adopted by a company that implement an EFQM model.

Our third hypothesis is based on the relationship between two criteria, Leadership and Strategy. Our results show also a positive relationship ( $\beta=0.520$, $\mathrm{p}<0.001)$. In this case, the behaviour and actions of the executive team create the culture, values and overall direction required for long-term success in organizations favourable to EFQM.

In hypothesis $\mathrm{H}_{4}$ we tested the relationship between People criterion and performance $(\beta=0.411, \mathrm{p}<0.001)$. Our results confirm the importance of how organizations implement, manage, develop and release the full potential of their people according to the advices included in this criterion of the EFQM, for 
attaining competitive advantages.

Finally, the last goal of this research was to determine whether or not the implementation of a SHRM approach could explain superior performance in organizations that follow the principles included in the People criterion of the model. In this case we analysed the mediating effect of a strategic perspective on HRM, with both direct and indirect effects. The first link (direct effect) examined the direct relationship between People and performance $\left(\mathrm{H}_{4}\right)$, while the second link (partial mediation) examined the same relationship with SHRM acting as a mediator. The results of the mediation link support our hypothesis. First, the partial mediation model explains more variance in performance than the direct effect model (0.329 compared with 0.398). Second, positive relationships exist between People and SHRM $(\beta=0.561, \mathrm{p}<0.001)$; and between SHRM and performance $(\beta=0.249, \mathrm{p}<0.001)$ (see Figure 1). Third, the significant relationship between People and performance in the direct effect model $(\beta=0.510, p<0.001)$ diminishes in the partial mediation model $(\beta=0.411$, $\mathrm{p}<0.001)$. Together these three points provide evidence that there is a discernible mediating effect of strategic HRM and that the partial mediation model represents a significant improvement over the direct effect model.

\section{Discussion and Conclusions.}

Regarding our first aim, it was confirmed that, from the EFQM model, managing people is conditioned by several factors. On the one hand, following the recommendations included in the criteria Leadership and Strategy of the model can shape the good implementation of People criterion practices according to this model. Both predictors are well supported by the literature and reflect the influence of senior management on SHRM (Chuang, Jackson, \& Jiang, 2016; Viitala et al., 2017).

Concerning the second aim, the proposed hypothesis is accepted, demonstrating that HRM needs to adopt a strategic perspective, so that it can mediate the relationship between personnel practices and performance, ensuring that the 
former generates HRM behaviour that contributes to improving organizational performance (Darwish et al., 2013). The combined effect of People criterion and SHRM appears to achieve better results in organizations that follow the EFQM model.

Van Schoten et al. (2016) Balbastre-Benavent and Canet-Giner (2011) and Haffer (2010) suggested in their studies that more research is needed to demonstrate the benefits of implementing the EFQM model and SHRM in an organization. Our study is a proof of the probable success that organizations may obtain when they follow this profile.

Additionally, it has been observed that the size of the companies' influence Strategy and People, shedding light on this issue, on which contrary results had been published in various studies (A. Calvo-Mora et al., 2015). In this sense, it can be stated that medium-sized companies that have the most consolidated policies get to align Strategy and HR issues, contrary to what, for example, may occur usually in smaller companies that do not have structured internal processes or, for example, do not have in-depth human resources policies.

The findings of the empirical study shed light on some unexplored arguments. In conclusion, our paper has shown that Leadership criterion has a positive effect on organizational Strategy criterion and personnel practices represented by People criterion of the EFQM model, while also strategy is positively associated with it. It has also been found in this research that following the principles included in the People criterion of the model affects positively organizational performance through SHRM. In this sense, the findings provided evidence of the mediating role of SHRM behaviour on the relationship between People criterion of EFQM model and performance. Specifically, the enabler criterion of People in the model is a determinant for developing strategic HRM behaviour and obtaining improvements in performance. In fact, the EFQM Model proposes to carry out as a transformational leadership, as well as an universalistic and proactive approach of HRM. This is aligned with the new perspective on HRM, which suggests that HRM is influenced directly by 
strategy, with the aim of attaining a major performance and success (Knies et al., 2017).

This supports assumption that HRM has a direct effect on performance but its influence is greater when HRM adopts a strategic perspective (Gao et al., 2016). HR managers will be asked to choose the best practices following the suggestions of the People criterion of the EFQM model, in order to improve results. For this purpose, they will need to consider the importance of implementing a SHRM approach that influence positively performance.

Nevertheless, the cross-sectional design of this research is a disadvantage. Even though the structural equations method was employed, interpretation of the causality between constructs should be accepted with caution (Tippins \& Sohi, 2003). In order to examine the causality of these relationships, future research should use longitudinal studies. Second, although this study uses a broad measure for organizational performance, the measure is subjective and could be complemented with objective and financial data.

For future research, we also identify three approaches that could enrich the study of the analysed relationships. First, we suggest that it would be helpful to examine which HRM practices are clearly linked to the model, and their impact to organizational performance. Second, our model analyses relationships among Leadership, Strategy and People. One of the main factors that is omitted from the model is organizational culture. In consequence, we suggest that future research should analyse the type of organizational culture required to foster the relationships in the model.

Finally, future research should study in depth the functioning of the EFQM model in relation with total quality models, especially in human resource topics. For example, it would be interesting to compare which human resource management practices are derived from EFQM and TQM or, even, from the ISO 9001 norm. 


\section{References}

Akhtar, S., Ding, D. Z., \& Le, G. (2008). Strategic HRM practices and their impact on company performance in Chinese enterprises. Human Resource Management, 47(1), 15-32. doi: 10.1002/hrm.20195

Ali, M., Lei, S., \& Wei, X.-Y. (2017). Mediating role of employee relations climate between strategic-HRM and organizational performance: An empirical study of Chinese banking sector. Journal of Innovation \& Knowledge. doi: 10.1016/j.jik.2016.12.003

Asag-Gau, L., \& Dierendonck, D. V. (2011). The impact of servant leadership on organisational commitment among the highly talented: the role of challenging work conditions and psychological empowerment. European Journal of International Management, 5(5), 463-483. doi: 10.1504/EJIM.2011.042174

Balbastre-Benavent, F., \& Canet-Giner, M. T. (2011). The strategy formation process in the EFQM Excellence Model: a critical review and new perspectives. Total Quality Management \& Business Excellence, 22(7), 727-742. doi: 10.1080/14783363.2011.585773

Baptiste, N. R. (2008). Tightening the link between employee wellbeing at work and performance: A new dimension for HRM. Management decision, 46(2), 284-309. doi: 10.1108/00251740810854168

Bayo-Moriones, A., Bello-Pintado, A., \& Merino-Diaz-de-Cerio, J. (2011). Quality assurance practices in the global supply chain: the effect of supplier localisation. International Journal of Production Research, 49(1), 255-268. doi: 10.1080/00207543.2010.508953

Bayo-Moriones, A., Merino-Díaz-de-Cerio, J., Escamilla-de-León, S. A., \& Selvam, R. M. (2011). The impact of ISO 9000 and EFQM on the use of flexible work practices. International Journal of Production Economics, 130(1), 33-42. doi: 10.1016/j.ijpe.2010.10.012

Bollen, K. A., \& Lennox, R. (1991). Conventional wisdom on measurement: a structural equation perspective. Psychological Bulletin, 110(2), 305-314. doi: 10.1037/0033-2909.110.2.305

Bonavia, T., \& Marin-Garcia, J. A. (2011). Integrating human resource management into lean production and their impact on organizational performance. International Journal of Manpower, 32(8), 923-938. doi: 10.1108/01437721111181679

Bou-Llusar, J. C., Escrig, A. B., Roca, V., \& Beltran, I. (2005). To what extent do enablers explain results in the EFQM excellence model? An empirical study. International Journal of Quality \& Reliability Management, 22(4), 337-353. doi: 10.1108/02656710510591192

Boxall, P., \& Purcell, J. (2003). Strategy and human resource management. Basingstoke and New York: Palgrave Macmillan. 
Calvo-Mora, A., Leal, A., \& Roldán, J. (2006). Using enablers of the EFQM model to manage institutions of higher education. Quality Assurance in Education, 14(2), 99-122. doi: 10.1108/09684880610662006

Calvo-Mora, A., Picón-Berjoyo, A., Ruiz-Moreno, C., \& Cauzo-Bottala, L. (2015). Contextual and mediation analysis between TQM critical factors and organisational results in the EFQM Excellence Model framework. International Journal of Production Research, 53(7), 2186-2201. doi: 10.1080/00207543.2014.975859

Calvo-Mora, A., Picón, A., Ruiz, C., \& Cauzo, L. (2013). The relationships between soft-hard TQM factors and key business results. International Journal of Operations \& Production Management, 34(1), 115-143. doi: doi:10.1108/IJOPM-09-2012-0355

Canet-Giner, M. T., \& Balbastre-Benavent, F. (2011). Rationality, participation and results: The case of the European excellence model in a Spanish services context. The Service Industries Journal, 31(12), 1995-2017. doi: 10.1080/02642069.2011.556191

Cañibano, A. (2013). Implementing innovative HRM: Trade-off effects on employee well-being. Management Decision, 51(3), 643-660

Cappelli, P., \& Crocker-Hefter, A. (1996). Distinctive human resources are firms' core competencies. Organizational Dynamics, 24(3), 7-22. doi: 10.1016/S0090-2616(96)90002-9

Corredor, P., \& Goñi, S. (2010). Quality awards and performance: is there a relationship? The TQM Journal, 22(5), 529-538. doi: 10.1108/17542731011072865

Chadwick, C., Super, J. F., \& Kwon, K. (2015). Resource orchestration in practice: CEO emphasis on SHRM, commitment-based HR systems, and firm performance. Strategic Management Journal, 36(3), 360-376. doi: $10.1002 / \mathrm{smj} .2217$

Chuang, C.-H., Jackson, S. E., \& Jiang, Y. (2016). Can knowledge-intensive teamwork be managed? Examining the roles of HRM systems, leadership, and tacit knowledge. Journal of management, 42(2), 524554. doi: $10.1177 / 0149206313478189$

Darwish, T. K., Singh, S., \& Mohamed, A. F. (2013). The role of strategic HR practices in organisational effectiveness: an empirical investigation in the country of Jordan. The International Journal of Human Resource Management, 24(17), 3343-3362. doi: 10.1080/09585192.2013.775174

Delery, E. J., \& Doty, D. H. (1996). Modes of theorizing in strategic human resource management: test of universalistic, contingency and configurational performance. Academy of Management Journal, 39(4), 802-835. doi: 10.2307/256713

Dijkstra, L. (1997). An empirical interpretation of the EFQM framework. European journal of work and organizational psychology, 6(3), 20. doi: 10.1080/135943297399097

Doeleman, H. J., Ten Have, S., \& Ahaus, C. T. B. (2013). Empirical evidence on applying the European Foundation for Quality Management 
Excellence Model, a literature review. Total Quality Management \& Business Excellence, 25(5-6), 439-460. doi: 10.1080/14783363.2013.862916

Doeleman, H. J., ten Have, S., \& Ahaus, K. (2012). The moderating role of leadership in the relationship between management control and business excellence. Total Quality Management \& Business Excellence, 23(5/6), 591-611. doi: 10.1080/14783363.2012.669935

EFQM. (2013). EFQM model for business excellence. Retrieved from http://www.efqm.org

Escrig, A. B., \& de Menezes, L. M. (2015). What characterizes leading companies within business excellence models? An analysis of "EFQM Recognized for Excellence" recipients in Spain. International Journal of Production Economics, 169, 362-375. doi: https://doi.org/10.1016/j.ijpe.2015.08.019

Eskildsen, J. K. (1998). Identifying the vital few using the European Foundation for Quality Management Model. Total Quality Management, 9(4/5), S92-S95. doi: 10.1080/0954412988631

Eskildsen, J. K., \& Dahlgaard, J. J. (2000). A causal model for employee satisfaction. Total Quality Management, 11(8), 1081-1094. doi: $10.1080 / 095441200440340$

Galpin, T., \& Whittington, J. L. (2012). Sustainability leadership: from strategy to results. Journal of Business Strategy, 33(4), 40-48. doi: $10.1108 / 02756661211242690$

Gao, Y., Zhou, Z., \& Wu, L.-Z. (2016). Strategic Orientation, Strategic Flexibility, and Firm Performance: The Important Role of SHRM Academy of Management Proceedings (Vol. 2016, pp. 16559): Academy of Management.

Gillet, N., \& Vandenberghe, C. (2014). Transformational Leadership and Organizational Commitment: The Mediating Role of Job Characteristics. Human Resource Development Quarterly, 25(3), 321347. doi: 10.1002/hrdq.21192

Gómez-López, R., Serrano-Bedia, A. M., \& López-Fernández, M. C. (2016). Motivations for implementing TQM through the EFQM model in Spain: an empirical investigation. Total Quality Management \& Business Excellence, 27(11-12), 1224-1245. doi: 10.1080/14783363.2015.1068688

Haffer, R. K. K. (2010). People management as indicator of business excellence: the Polish and Danish perspectives. The TQM Journal, 22(4), 386-398

Hanks, S. H. (2012). Leadership Potential, Leadership Discretion Recent Academic Research on People and Strategy. People \& Strategy 35(3), 10-11. doi: 83003744

Harpaz, I., \& Meshoulam, I. (2010). The meaning of work, employment relations, and strategic human resources management in Israel. Human Resource Management Review, 20(3), 212-223. doi: 


\subsection{6/j.hrmr.2009.08.009}

Heavey, C., \& Murphy, E. (2012). A proposed cooperation framework for organisations and their leaders. Management Decision, 50(6), 993-1000. doi: $10.1108 / 00251741211238292$

Hoyle, R. H., \& Panter, A. T. (1995). Writing about structural equation modeling. Thousand Oaks: Sage.

Jöreskog, K. G., \& Sörbom, D. (1996). LISREL 8 user's reference guide. Chicago: Scientific Software International.

Knies, E., Boselie, P., Gould-Williams, J., \& Vandenabeele, W. (2017). Strategic human resource management and public sector performance: context matters, 1 , 1-13. doi: 10.1080/09585192.2017.1407088

Laschinger, H. K. S., \& Fida, R. (2015). Linking nurses' perceptions of patient care quality to job satisfaction: the role of authentic leadership and empowering professional practice environments. Journal of Nursing Administration, 45(5), 276-283. doi: 10.1097/NNA.0000000000000198

Laureani, A., \& Antony, J. (2017). Leadership characteristics for lean six sigma. Total Quality Management \& Business Excellence, 28(3-4), 405-426. doi: 10.1080/14783363.2015.1090291

Lengnick-Hall, C. A., Beck, T. E., \& Lengnick-Hall, M. L. (2011). Developing a capacity for organizational resilience through strategic human resource management. Human Resource Management Review, 21(3), 243-255. doi: 10.1016/j.hrmr.2010.07.001

Lengnick-Hall, M. L., Lengnick-Hall, C. A., \& Rigsbee, C. M. (2012). Strategic human resource management and supply chain orientation. Human Resource Management Review, 23(4), 366-377

Lengnick-Hall, M. L., Lengnick Hall, C. A., Andrade, L. S., \& Drake, B. (2009). Strategic human resource management: The evolution of the field. Human resource management review, 19(2), 64-85

Lowe, K. B., Kroeck, K. G., \& Sivasubramaniam, N. (1996). Efectiveness correlates of transformational and transactional leadership: A metaanalytic review of the MLQ literature. Leadership Quarterly, 7(3), 385425. doi: 10.1016/S1048-9843(96)90027-2

MacKenzie, S. B., Podsakoff, P. M., \& Rich, G. A. (2001). Transformational and Transactional Leadership and Salesperson Performance. Journal of the Academy of Marketing Science, 29(2), 115-134. doi: 10.1177/03079459994506

Maleyeff, J. (2006). Exploration of internal service systems using lean principles. Management decision, 44(5), 674-689. doi: 10.1108/00251740610668914

Martínez-Jurado, P. J., Moyano-Fuentes, J., \& Gómez, P. J. (2013). HR management during lean production adoption. Management Decision, 51(4), 742-760. doi: 10.1108/00251741311326545

Masa'deh, R. e., Obeidat, B. Y., \& Tarhini, A. (2016). A Jordanian empirical study of the associations among transformational leadership, transactional leadership, knowledge sharing, job performance, and firm 
performance: A structural equation modelling approach. Journal of Management Development, 35(5), 681-705. doi: 10.1108/JMD-09-20150134

Matthies-Baraibar, C., Arcelay-Salazar, A., Cantero-González, D., ColinaAlonso, A., García-Urbaneja, M., González-Llinares, R. M., . . . NuñoSolinís, R. (2014). Is organizational progress in the EFQM model related to employee satisfaction? BMC health services research, 14(1), 468. doi: 10.1186/1472-6963-14-468

Menguc, B., Auh, S., \& Shih, E. (2007). Transformational leadership and market orientation: Implications for the implementation of competitive strategies and business unit performance. Journal of Business Research, 60(4), 314-321. doi: 10.1016/j.jbusres.2006.12.008

Muindi, J. M. (2017). Effectiveness of Strategic Human Resource Management Practices in Enhancing Performance: A Case of the Office of the Attorney-General and Department Of Justice in Kenya. United States International University-Africa.

Nabitz, U., Jansen, P., Van der Voet, S., \& Van den Brink, W. (2009). Psychosocial work conditions and work stress in an innovating addiction treatment centre. Consequences for the EFQM Excellence Model. Total Quality Management \& Business Excellence, 20(3), 267-281. doi: 10.1080/14783360902719410

Ngo, H. Y., Lau, C., \& Foley, S. (2008). Strategic human resource management, firm performance, and employee relations climate in China. Human Resource Management, 47(1), 73-90. doi: 10.1002/hrm.20198

Park, Y., \& Jacobs, R. L. (2011). The influence of investment in workplace learning on learning outcomes and organizational performance. Human Resource Development Quarterly, 22(4), 437-458. doi: 10.1002/hrdq.20085

Pattanayak, T. K., \& Sahoo, K. (2017). Strategic Human Resource Management (SHRM) Initiatives for Organisational Effectiveness: A Case Study of a Process Unit. Siddhant-A Journal of Decision Making, 17(4), 343-350. doi: 10.1016/j.jik.2016.12.003

Prabhakar, G. V., \& Yaseen, A. (2016). Decision-making styles and leadership: evidences from the UAE. International Journal of Management Development, 1(4), 287-306. doi: doi.org/10.1504/IJMD.2016.083582

Prajogo, D. I., \& Sohal, A. S. (2006). The relationship between organization strategy, total quality management (TQM), and organization performance-the mediating role of TQM. European Journal of Operational Research, 168(1), 35-50. doi: http://dx.doi.org/10.1016/j.ejor.2004.03.033

Raharjo, H., Guglielmetti Mugion, R., Eriksson, H., Gremyr, I., Di Pietro, L., \& Renzi, M. F. (2015). Excellence models in the public sector. Relationships between enablers and results. International Journal of Quality and Service Sciences, 7(1), 120-135. doi: 10.1108/IJQSS-01- 
2015-0011

Sadeh, E., \& Arumugam, V. C. (2010). Interrelationships among EFQM excellence criteria in Iranian industrial SMEs. European Journal of Economics, Finance and Administrative Sciences(19), 155-167. doi: edselc.2-52.0-77953970045

Sadeh, E., Arumugam, V. C., \& Malarvizhi, C. A. (2013). Integration of EFQM framework and quality information systems. Total Quality Management \& Business Excellence, 24(1-2), 188-209. doi: 10.1080/14783363.2012.756744

Samuelsson, P., \& Nilsson, L. E. (2002). Self-assessment practices in large organisations: Experiences from using the EFQM excellence model. International Journal of Quality \& Reliability Management, 19(1), 1023. doi: doi:10.1108/02656710210413426

Santos-Vijande, M. L., \& Álvarez-González, L. I. (2007). TQM and firms performance: An EFQM excellence model research based survey. Int. Journal of Business Science and Applied Management, 2(2), 21-41

Saridakis, G., Lai, Y., \& Cooper, C. L. (2017). Exploring the relationship between HRM and firm performance: A meta-analysis of longitudinal studies. Human Resource Management Review, 27(1), 87-96. doi: https://doi.org/10.1016/j.hrmr.2016.09.005

Singh, J., \& Singh, H. (2014). Performance enhancement of a manufacturing industry by using continuous improvement strategies - a case study. International Journal of Productivity and Quality Management, 14(1), 36-65. doi: 10.1504/IJPQM.2014.063165

Sparrow, P. (2016). Strategic HRM, Innovation and HR Delivery for Human Resource Management, Innovation and Performance Human Resource Management, Innovation and Performance (pp. 15-31). United Kingdom: Springer.

Suarez, E., Calvo-Mora, A., \& Roldán, J. L. (2016). The role of strategic planning in excellence management systems. European Journal of Operational Research, 248(2), 532-542. doi: 10.1016/j.ejor.2015.07.008

Sun, L.-Y., \& Pan, W. (2011). Differentiation strategy, high-performance human resource practices, and firm performance: moderation by employee commitment. The International Journal of Human Resource Management, 22(15), 3068-3079. doi: 10.1080/09585192.2011.560860

Tippins, M. J., \& Sohi, R. S. (2003). IT competency and firm performance: Is organizational learning a missing link? Strategic Management Journal, 24(8), 745-761. doi: 10.1002/smj.337

Tracey, J. B. (2012). A contextual, flexibility-based model of the HR-firm performance relationship. Management decision, 50(5), 909-924. doi: 10.1108/00251741211227609

Tzabbar, D., Tzafrir, S., \& Baruch, Y. (2017). A bridge over troubled water: Replication, integration and extension of the relationship between HRM practices and organizational performance using moderating metaanalysis. Human Resource Management Review, 27(1), 134-148. doi: 
10.1016/j.hrmr.2016.08.002

Ugboro, I. O., \& Obeng, K. (2000). Top management leadership, employee empowerment, job satisfaction, and customer satisfaction in TQM organizations: an empirical study. Journal of Quality Management, 5(2), 247-272. doi: dx.doi.org/10.1016/S1084-8568(01)00023-2

Van Schoten, S., de Blok, C., Spreeuwenberg, P., Groenewegen, P., \& Wagner, C. (2016). The EFQM Model as a framework for total quality management in healthcare: Results of a longitudinal quantitative study. International Journal of Operations \& Production Management, 36(8), 901-922. doi: 10.1108/IJOPM-03-2015-0139

Vermeeren, B., Kuipers, B., \& Steijn, B. (2014). Does leadership style make a difference? Linking HRM, job satisfaction, and organizational performance. Review of Public Personnel Administration, 34(2), 174195. doi: $10.1177 / 0734371 X 13510853$

Viitala, R., Viitala, R., Kultalahti, S., Kultalahti, S., Kangas, H., \& Kangas, H. (2017). Does strategic leadership development feature in managers' responses to future HRM challenges? Leadership \& Organization Development Journal, 38(4), 576-587. doi: 10.1108/LODJ-02-20160035

Wan Hooi, L., \& Sing Ngui, K. (2014). Enhancing organizational performance of Malaysian SMEs. International Journal of Manpower, 35(7), 973995. doi: doi:10.1108/IJM-04-2012-0059

Wei, L., Liu, J., Zhang, Y., \& Chiu, R. K. (2008). The role of corporate culture in the process of strategic human resource management: Evidence from Chinese enterprises. Human Resource Management, 47(4), 777-794. doi: 10.1002/hrm.20244

Wongrassamee, S., Gardiner, P. D., \& Simmons, J. E. L. (2003). Performance measurement tools: the Balanced Scorecard and the EFQM Excellence Model. Measuring Business Excellence, 7(1), 14-29. doi: 10.1108/13683040310466690

Wright, P. M., Dunford, B. B., \& Snell, S. A. (2001). Human resources and the resource based view of the firm. Journal of Management, 27(6), 701721. doi: 10.1177/014920630102700607

Wright, P. M., \& McMahan, G. C. (1992). Theoretical perspectives for strategic human resource management. Journal of Management Studies, 18(2), 295-320. doi: 10.1177/014920639201800205

Wright, P. M., \& Snell, S. A. (1991). Toward an integrative view of strategic human resource management. Human Resource Management Review, 1(3), 203-225. doi: 10.1016/1053-4822(91)90015-5

Xie, L. X. (2007). A study of strategic human resource management on Taiwanese enterprises. Central South University (People's Republic of China), Ann Arbor (United States).

Youssef, E. M., Youssef, M. A., \& Ahmed, A. M. M. B. (2014). Total quality management intensity and its impact on HRM practices in manufacturing firms. International Journal of Productivity and Quality 
Management, 13(4), 495 - 512. doi: 10.1504/IJPQM.2014.062224

Zarrabi, F., \& Vahedi, M. (2012). Alignment Between Technology Strategy And Leadership. Procedia - Social and Behavioral Sciences, 41(0), 2328. doi: 10.1016/j.sbspro.2012.04.003

Zhu, C. J., Cooper, B. K., Thomson, S. B., De Cieri, H., \& Zhao, S. (2013). Strategic integration of HRM and firm performance in a changing environment in China: the impact of organisational effectiveness as a mediator. The International Journal of Human Resource Management, 24(15), 2985-3001. doi: 10.1080/09585192.2013.763845

Zink, K. J., \& Schmidt, A. (1995). Measuring universities against the European Quality Award criteria. Total Quality Management, 6(5\&6), 547-561. doi: 10.1080/09544129550035206 


\section{Appendix}

1.- Items included to measure EFQM "People criterion":

Regarding personnel:

- Employees and their delegates are involved in the development of human resource strategies.

- The personnel strategy is aligned with the organizational strategy and structure.

- Training and development plans are adjusted to the current and future capabilities of the organization.

- Capability in teamwork is developed.

- Individual and team participation in improvement activities is encouraged.

- Involvement and creative and innovative behavior on the part of employees are stimulated.

- Vertical and horizontal communication is encouraged.

- Knowledge sharing is promoted.

- Reward, compensation and dismissal processes are aligned with the organizational strategy.

- Acknowledgment is given to employees in order to get them involved.

2.- Items intended to measure leadership:

Regarding the managers of your company...

- They are actively involved in improvement activities.

- Cooperation among members in the organization is stimulated.

- The structure of the organization is proportioned to support the implantation of the policy and strategy.

- They are interested in the measurement, review and improvement of process results.

- They strive to meet customers' needs.

- They strive to meet society's needs.

- They are accessible, listen actively and respond to the people that make up the organization.

- They recognize the efforts of people and teams on all organizational levels.

- They guarantee the investment, resources and support needed for changes.

- They communicate changes and reasons that have caused them to employees and 
other stakeholders, who may be affected by them.

3.- Items conducted to measure SHRM:

Regarding the strategic planning process of your organization...

- Managers' characteristics are in agreement with strategic planning.

- The needed managing style for the long-term operation of the company is identified.

- Compensation systems of the Management team in order to achieve long-term goals are modified.

- Selection types to help to implement the company strategies are designed.

- Key personnel are evaluated based on its potential to carry out strategic aims.

- Job positions are described based on what work can suppose in future.

- Personnel development programs to support strategic changes are led.

- Human resources department proportionate human resources information for strategic decisions.

- A human resources planning exists in the company, with clear and formal proceedings.

- The senior management is capable of communicate effectively the goals and strategies to employees.

4.- Items included to measure Performance:

Indicate how each of the following measures evolved in the last three years:

- The opinion of clients about the quality of design of our products.

- The opinion of clients about the quality of production of our products.

- The market value of the company.

- The quantity of complaints and claims on behalf of clients.

- The motivation of employees to improve the organization.

- The participation of employees in the improvement of the organization.

- Security and hygiene in the workplace.

- The qualifications of employees.

- The knowledge of our organization of its relationships with society.

- The image of the organization in relation to society.

- Satisfaction with the relationships with public administrations. 
- The acknowledgement of external bodies such as entrepreneurial, public or union organizations.

- The productivity of our organization.

- The unit production cost of our products.

- The benefits of our organization.

- The profitability of our organization. 
Table 1. Sample Characteristics.

\begin{tabular}{|l|l|}
\hline \multicolumn{2}{|c|}{ Activity Sectors } \\
\hline Manufacture of textiles & $4.98 \%$ \\
\hline Manufacture of leather and related products & $17.41 \%$ \\
\hline Manufacture of paper and paper products & $1.00 \%$ \\
\hline Printing and reproduction of recorded media & $3.48 \%$ \\
\hline Manufacture of chemicals and chemical products & $3.98 \%$ \\
\hline $\begin{array}{l}\text { Manufacture of basic pharmaceutical products and pharmaceutical } \\
\text { preparations }\end{array}$ & $1.49 \%$ \\
\hline Manufacture of rubber and plastic products & $9.45 \%$ \\
\hline Metal mechanic & $19.40 \%$ \\
\hline Manufacture of electrical equipment & $4.48 \%$ \\
\hline Manufacture of furniture & $27.86 \%$ \\
\hline Other manufacturing & $6.47 \%$ \\
\hline \multicolumn{1}{|c|}{ Sales Volume (mill. $€$ ) } & \\
\hline$<10$ & $31.0 \%$ \\
\hline $10-50$ & $43.5 \%$ \\
\hline $50-100$ & $14.0 \%$ \\
\hline$>100$ & $11.5 \%$ \\
\hline \multicolumn{2}{|c|}{} \\
\hline $55-99$ & $45.0 \%$ \\
\hline $100-250$ & $30.5 \%$ \\
\hline $250-500$ & $24.5 \%$ \\
\hline \multicolumn{2}{|c}{ Notal: 200 } \\
\hline
\end{tabular}


Table 2: Descriptive statistics and correlation matrix.

\begin{tabular}{|c|c|c|c|c|c|c|c|c|c|}
\hline \multirow{2}{*}{ Construct } & \multirow{2}{*}{ Mean } & \multirow{2}{*}{$\begin{array}{l}\text { St. } \\
\text { Dev. }\end{array}$} & \multicolumn{7}{|c|}{ Correlation matrix } \\
\hline & & & 1 & 2 & 3 & 4 & 5 & 6 & 7 \\
\hline 1. Leadership & 3.961 & 0.492 & 1 & & & & & & \\
\hline $\begin{array}{l}\text { 2. Policy and } \\
\text { Strategy }\end{array}$ & 3.784 & 0.483 & $0.689^{* *}$ & 1 & & & & & \\
\hline 3. People & 4.076 & 0.442 & $0.765^{* *}$ & $0.713^{* *}$ & 1 & & & & \\
\hline $\begin{array}{l}\text { 4. Strategic } \\
\text { HRM }\end{array}$ & 3.595 & 0.468 & $0.538^{* *}$ & $0.499^{* *}$ & $0.609^{* *}$ & 1 & & & \\
\hline $\begin{array}{l}5 . \\
\text { Performance }\end{array}$ & 3.996 & 0.408 & $0.473^{* *}$ & $0.509^{* *}$ & $0.594^{* *}$ & $0.525^{* *}$ & 1 & & \\
\hline 6. Age & 3.133 & 0.554 & -0.038 & 0.065 & 0.017 & -0.027 & 0.037 & 1 & \\
\hline 7. Size & 4.845 & 0.693 & $0.280^{* *}$ & $0.387^{* *}$ & $0.413^{* * *}$ & $0.344^{* *}$ & $0.329^{* * *}$ & 0.044 & 1 \\
\hline
\end{tabular}


Table 3: Construct structural model

\begin{tabular}{|c|c|c|c|c|}
\hline Hypotheses & Model relationships & $\begin{array}{l}\text { Stand } \\
\text { parameter }\end{array}$ & t-value & $\begin{array}{l}\text { Empiric } \\
\text { conclusion }\end{array}$ \\
\hline $\mathrm{H}_{1}$ & Strategy $\rightarrow$ People & 0.294 & $4.995^{* * *}$ & Accepted \\
\hline $\mathrm{H}_{2}$ & Leadership $\rightarrow$ People & 0.635 & $9.188^{* * *}$ & Accepted \\
\hline $\mathrm{H}_{3}$ & Leadership $\rightarrow$ Strategy & 0.520 & $12.402^{* * *}$ & Accepted \\
\hline $\mathrm{H}_{4}$ & People $\rightarrow$ Performance & 0.411 & $5.716^{* * *}$ & Accepted \\
\hline \multirow[t]{10}{*}{$\mathrm{H}_{5}$} & People $\rightarrow$ SRHM & 0.561 & $9.177^{* * *}$ & \multirow[t]{2}{*}{ Accepted } \\
\hline & SRHM $\rightarrow$ Performance & 0.249 & $3.560^{* * *}$ & \\
\hline & Size $\rightarrow$ Strategy & 0.204 & $3.993^{* * *}$ & \\
\hline & Size $\rightarrow$ People & 0.152 & $3.442^{* * *}$ & \\
\hline & Size $\rightarrow$ SRHM & 0.113 & 1.850 & \\
\hline & Size $\rightarrow$ Performance & 0.071 & 1.167 & \\
\hline & Age $\rightarrow$ Strategy & 0.077 & 1.568 & \\
\hline & Age $\rightarrow$ People & 0.010 & 0.242 & \\
\hline & Age $\rightarrow$ SRHM & -0.044 & 0.783 & \\
\hline & Age $\rightarrow$ Performance & 0.032 & 0.587 & \\
\hline
\end{tabular}

Note: $* * * p<0.001$; Fit statistics for measurement model: $\chi_{(4)}^{2}=7.606 ; \mathrm{P}>0.10$, $\mathrm{CFI}=0.994, \mathrm{IFI}=0.994, \mathrm{GFI}=0.989$, $\mathrm{RMSEA}=0.067$. 
Figure 1: The EFQM Excellence Model

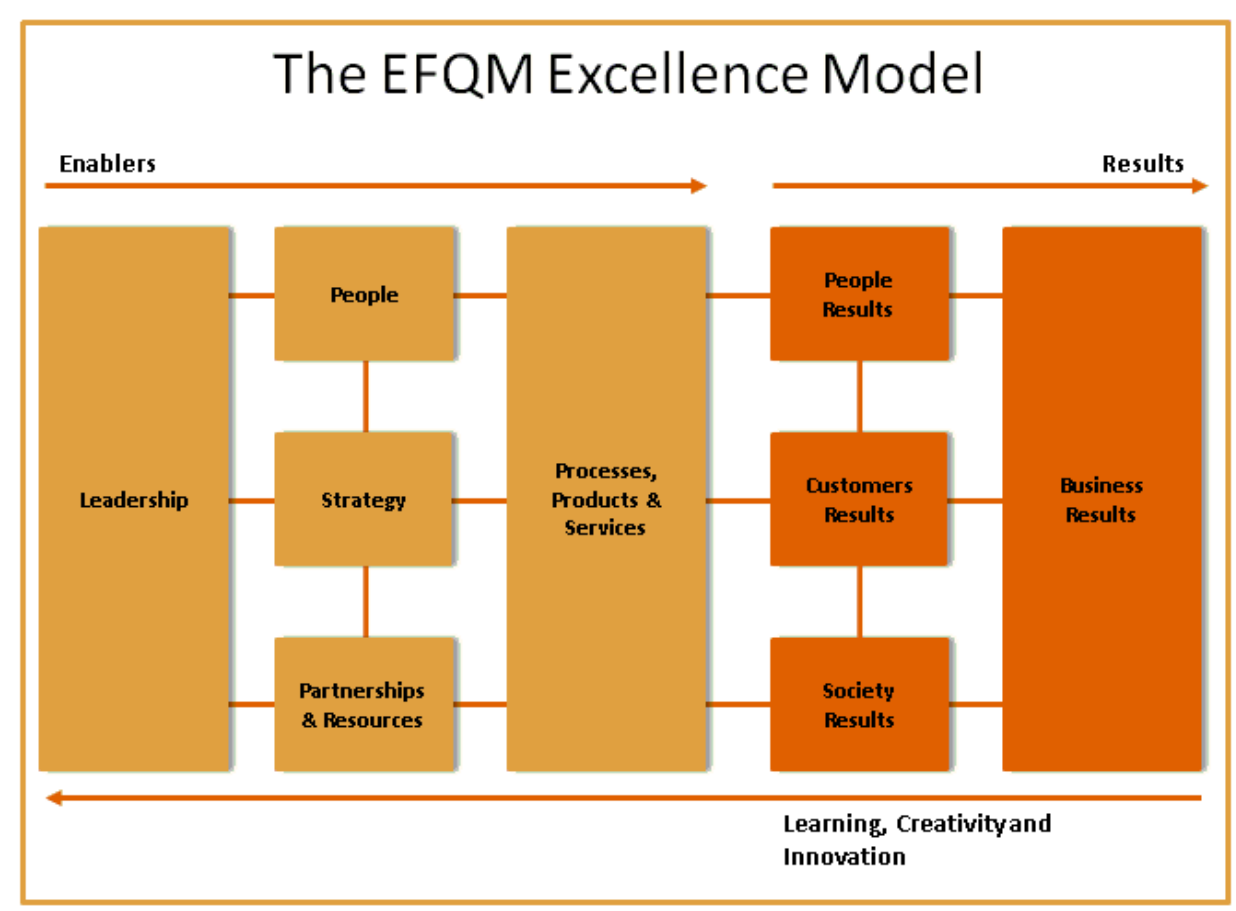

Source: EFQM (2013). 
Figure 2: Results of testing the hypotheses.

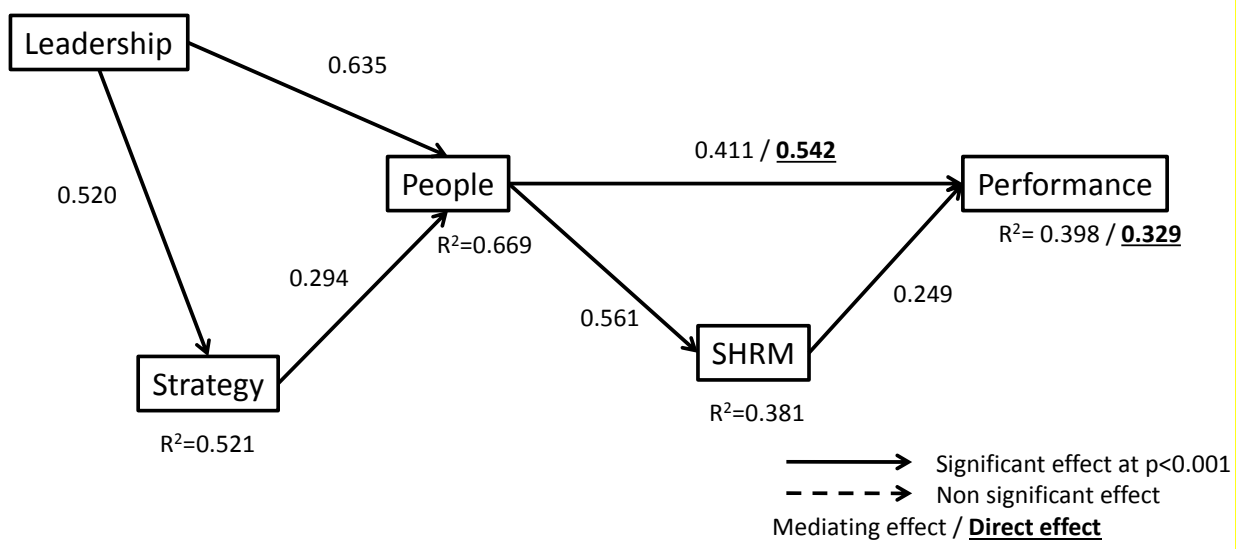

